\title{
Capacity estimation of small surface water bodies using RS and GIS
}

N. Hari, A. Mani and G. Manoj Kumar

Received : 16.06.2017; Revised : 27.02.2018; Accepted : 10.03.2018

See end of the Paper for authors' affiliation

Correspondence to :

\section{N. Hari}

Department of Soil and Water Engineering, College of Agricultural Engineering (ANGRAU), Bapatla (A.P.) India

Email : harinaik1301@ gmail. com
-ABSTRACT : Surface water bodies are the major source for irrigation in India. Information on surface water bodies such as water spread area, volume of water stored in a water body is useful for understanding the availability of water resources for the crop season in a river basin / sub basin. The study extensively used satellite based techniques for the estimation of surface water spread at regional level and at temporal scale to facilitate mapping, monitoring visualization of the dynamics unlike conventional methods. Geospatial database on water bodies information has been created for the study area Krishna middle sub basin. The study considers only water bodies where water is stored for irrigation purpose such as reservoirs, tanks, ponds, etc excluding rivers. Study is focused on use of RS and GIS techniques with extensive use of Image processing and GIS software like ERDAS Imagine, ARC Desktop GIS and analyses the spatio- temporal water body layers. Quantitative estimates on WSA under water bodies are worked for analyzing inter / intra seasonal / annual analysis. The present study has brought out geospatial database and provided scope for sub regional / regional analysis. Estimation of regional surface water storage is estimated with separate methodology for larger and smaller water bodies. This is demonstrated within a sub basin namely Krishna middle sub basin. Storage in larger water bodies is estimated by developing satellite based Area -Capacity curves related to Elevation values on the date satellite data acquisition. Storage in smaller water bodies is estimated with the help a methodology frame work developed in this study using digital elevation models, stream order and relating to the extensive observations made on elevation difference between upstream and downstream of water bodies. The study has brought out suitable spatio-temporal information of water bodies useful for analyzing operational issues related to water resources availability. The information generated can be made use for web based regional analysis and for public domain with suitable visualization tools.

- KEY WORDS : Water bodies, Capacity, Water spread area, Remote sensing, GIS

- HOW TO CITE THIS PAPER : Hari, N., Mani, A. and Kumar, G. Manoj (2018). Capacity estimation of small surface water bodies using RS and GIS. Internat. J. Agric. Engg., 11(1) : 175-179, DOI: 10.15740/ HAS/IJAE/11.1/175-179. 